\title{
Delivering Value for the Patients in the Healthcare System Framework: An Integrated Approach
}

\author{
Alexandru-Bogdan Ursoiu ${ }^{1}$ \\ The Bucharest University of Economic Studies, Romania ${ }^{1}$
}

\begin{abstract}
This study explores the coordinates for strategic adaptation of the healthcare services suppliers, in the framework of different setups of systems with the objective to deliver consistent value for their patients' fulfilment. Given the healthcare industry specifics, the general variations of elements and the strategic choices are substantially impacted by the manner in which the healthcare systems are designed and how they are evolving. The prosed approach is integrative, aiming to provide both academics and practicians with a perspective on encompassing medical business development, taking into account the specific opportunities provided by the combination of elements from each of the main models of healthcare systems, in various individual contexts. This examination supports the proper positioning of the patients is as the focal point of the business, aiming at proving them with the best value and efficiently developing the business on the long term in connection with the market reality.
\end{abstract}

Keywords: Consumer value, Healthcare systems, Marketing mix, Patient satisfaction

\section{INTRODUCTION}

Based on the guidelines provided by The World Health Organization, healthcare systems must pursue the accomplishment of a decent wellbeing for the population and support its continuous improvement [1]. The medical services should be provided both in an equitable manner for all involved entities and as efficiently as possible, avoiding any waste of resources. In order to better satisfy the patients by providing value for them, an integrated approach based on the multi-disciplinary science of marketing can genuinely help the medical services providers to build up the business solidly around the genuine requirements of the patients, by adapting the strategies to the achieve the best possible integration of positive elements from the different healthcare frameworks. In essence, current health systems are based on a series of organizational models whose application covers aspects of the nature of the entities involved, the flows of specific activities, the mechanisms for purchasing medical products and services, the rights and obligations of patients, etc. In this context, at the level of each state acts a specific set of factors that determine the need for a specific mixture of converging elements from the theoretical models of organization of health systems.

The basic models whose theoretical architecture underlies the organization of current health systems are the national Beveridge-type health service system, the Bismarck-type national social health insurance system and the dominated private health insurance system [2], to which is added a fourth model characterized by the lack of formal organization, the one based on direct interactions resulting from the relatively unrestricted meeting of demand and supply. The optimal variant of organization at the level of a state is not a generally valid one, but must be chosen and implemented according to the situation of the respective state, in order to support the achievement of the desired performance [3]. As society advances and economies interconnect, health systems have become less and less rigid, undergoing continuous transformations and adaptations, so that in the capitalist world these systems tend to represent versions of combinations of elements from classical models, in various proportion. This integration necessarily requires continuous adaptation to national specificities in order to ensure the fulfilment of the desire to improve health and to be compatible with existing resources.

The value of a health system does not derive so much from similar characteristics that are successful in several countries [4], but especially from capitalizing on the context in which that system is implemented and adjusted according to needs and resources, because medical services is a very highly dependent on the interaction. From the perspective of capitalizing on the existing potential, as shown by [5], the marketing mix can be considered a manifestation of organizations' resources. As described in [6], the marketing mix represents the arrangement of strategic marketing tools addressing product, price, placement and promotion decisions, in order to deliver the desired reaction from its target market, comprising everything the firm can do to connect with customers and provide benefits for them. A good marketing strategy mixes those components into coordinated programs intended to accomplish the organization's building up of a solid and profitable position on the desired market. 


\section{MATERIALS AND METHODS}

This study has a preponderant theoretical nature, based on content analysis of data from secondary sources regarding healthcare and economics. In the process of analysis, the data was investigated and correlated in order to produce meaningful information, that, in turn, was synthetised in order to produce relevant conclusions on the most advisable ways of action in terms of practical business planning for healthcare services providers.

\section{RESULTS AND DISCUSSION}

The healthcare services industry is probably one the best illustration of a business field where the most significant marketing lessons can be implemented. With a perfect moral approach, the marketing capacities, strategically executed and accompanied with the suitable economic instruments, can contribute unequivocally to the conveyance an extraordinary value that makes the patient delighted. Fundamentally, the advancement of a quality economic strategy for the medical care administrations should accomplish two significant targets, as it needs to serve the patient's wellbeing assisting him with accomplishing an undeniable degree of fulfilment and simultaneously aiming to help the business operate efficiently. All the four fundamental frameworks not just have different adaptations to the territorial context, yet they even exist together in different extents making a melange that is rather individualised for each country.

\begin{tabular}{|c|c|}
\hline NATIONAL HEALTHCARE SERVICE SYSTEM & SOCIAL INSURANCE SYSTEM \\
\hline * The Beveridge Doctrine & * The Bismarck Doctrine \\
\hline * Desideratum of general access for all citizens & * Desideratum to protect citizens and promote better living \\
\hline * Healthcare mainly supported from the state budget & * Mandatory insurance if affordable \\
\hline PRIVATE INSURANCE SYSTEM & DIRECT INTERACTION SYSTEM \\
\hline $\begin{array}{l}\text { * Free initiative is considered to be the driving force for progress } \\
\text { * Risk assessments by insurers }\end{array}$ & $\begin{array}{l}\text { * Based on either lack of resources or lack of interest for a more } \\
\text { organized system }\end{array}$ \\
\hline * Permanent adaptation to the dynamics of needs & * Can substitute any component of organized systems \\
\hline * Focus on satisfying demand in profitable terms & * Can not completely substitute for any organized system because \\
\hline * Intense competition & of its lack of predictability \\
\hline
\end{tabular}

Fig. 1 Characteristics of healthcare service systems (Source: author drawing)

A. Delivering Value in the Framework of the National Healthcare System

The national health services system is based on a doctrine that aims to ensure equal access to health care for all citizens, being built on the guidelines developed by William Beveridge. Access to medical services is made without direct payments, but through funding from state budgets, which in turn are supported mainly by taxes [7]. Overall, those who need medical services benefit from them based on residence, similar to other public services such as firefighters, basic education and so on.

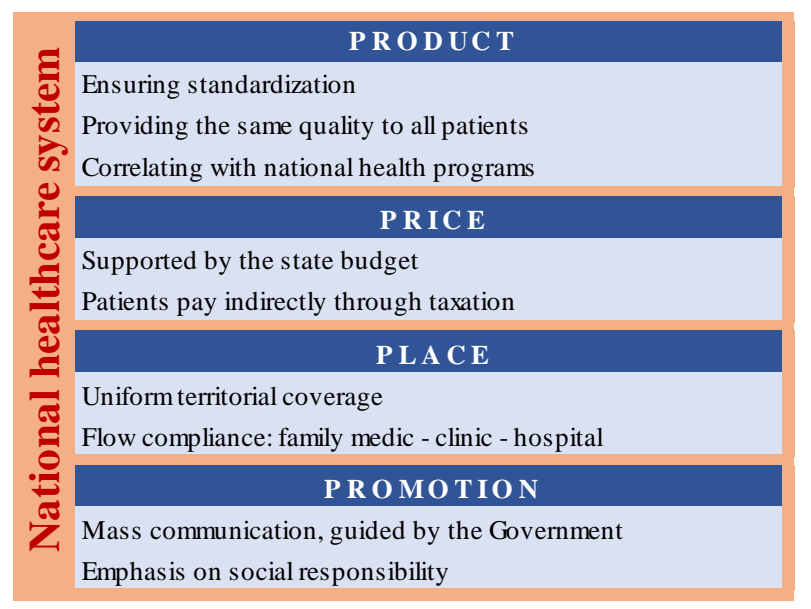

Fig. 2 Marketing decisions under the national healthcare service system (Source: author drawing)

It is considered as a health system with high addressability and profitability, which determines a favourable impact on the general health condition under conditions of good control possibilities [8]. Usually, the service providers are from the 


\section{DOI: $10.17148 /$ IARJSET.2021.8215}

public sector, especially the large units, and the quality level at which the services rise is strongly correlated with the evolution of the economy as a whole and the political priorities assumed.

The product policy within the marketing mix of medical services must first of all adapt to the need to standardize the supply parameters. Whether it is the set of state units, or that of private providers (whose "client" is also the "state", given that it provides funding based on the types of services to be provided to the population), medical services on which they offer must have the same level of accessibility and quality, as far as possible, on the whole spectrum of cases. Development factors are correlated with the strategic priorities defined at central level, usually expressed through national health programs.

From the point of view of price policy, marketing options must take into account in particular the fact that the financing is provided from the state budget. By default, costs must be strictly within the given budget envelope and there are minimal possibilities for patients to transfer additional costs, even if they could be justified. Basically, the beneficiaries of services paid in advance through taxation, the capital flow being determined by the level of income and not by the risk group. To some extent, marketing efforts must consider securing funding by attracting as many patients as possible, on the principle that money follows the patient [9]. Social solidarity remains the responsibility of the state, which will provide funding for medical units and for the treatment of disadvantaged people. If efforts to ensure high patient satisfaction could lead to cost overruns, they can be supported mainly by additional funding from the government, so as to ensure access to quality health services, the use of which does not expose beneficiaries of financial difficulties 10 , patients receiving care and providers being able to support their activity.

Distribution policy adapts marketing efforts based on the need for the widest and most homogeneous coverage of the territory, with a pyramidal structure of service providers by area: based on many family medicine providers, then polyclinics, followed by focus on highly specialized clinics, local hospitals and, at the top, the largest, metropolitan and regional hospitals, with the most developed research capacities, with university centres, etc. Usually, the goal of $100 \%$ population coverage tends to be achieved [11], and where this is not possible, completion is ensured on time, for example through health insurance.

Marketing promotion is usually based on topics of national or local interest, being in line with the issues addressed at the governmental level. Most of the messages are transmitted through the mass channels, not focusing on personalization, but on the impact on the population as a whole. One of the favourite topics is that of social responsibility, to which are subsumed aspects related to the need to adopt certain behaviours or limit others, in order to increase the overall level of health, limit infections, prevent risk factors, support efforts to ensuring the continuity of public services.

\section{B. Delivering Value in the Framework of the Social Insurance System}

National health insurance aims at national health care through a mandatory contribution framework, which can be, as the case may be, divided between the employee and the employer, or predominantly in charge of one of them. It is based on a doctrine developed by the Prussian Chancellor Otto von Bismarck in the 19th century and was initially based on protecting the beneficiaries in the event of accidents and illness, as well as extending the safety of decent living conditions after retirement [12], currently being extended to cover the entire population on the basis of tax contribution. Social protection works by assimilating with contributory periods in well-defined cases for disadvantaged or non-income categories.

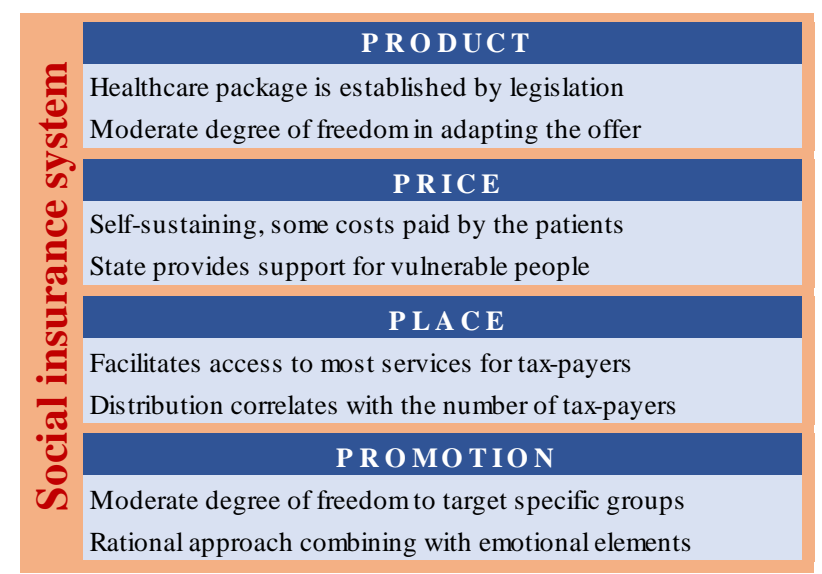

Fig. 3 Marketing decisions under the social insurance system (Source: author drawing) 


\section{DOI: $10.17148 /$ IARJSET.2021.8215}

The operators of the insurance funds are either wholly state-owned or separate entities under state control, operating in a regime of complementarity and not of competition. The content of the basic health package is rigorously established by the state, which causes providers to compete with similar basic services. However, product policy differentiation, as a strategic marketing option, can be better implemented than in the case of Beveridge-type systems.

In many cases, in order to be able to carry out contracts with state health insurance companies, medical units must first obtain accreditation from an authority for health quality management, based on the fulfilment of a set of service quality indicators. The way to fulfil these indicators is moderately flexible, without a single solution, but only criteria to be met. For example, informing and guiding patients in the medical unit can be achieved through a flexible mix of panels, leaflets, guidance systems, electronic display and so on, the emphasis being on the effectiveness of approaches.

Marketing can permanently design and adjust medical services either to fit the package provided by state insurance, or to exceed the package by providing additional funding from other sources, or even by ignoring the state package and providing separate services, if available and claimants are able to pay (for example, medical aesthetics as an end in itself, unrelated to restorative medicine).

In pricing policy, the dominant aspect that is taken into account in directing marketing efforts is the need to transfer some costs to the patient directly. Thus, if one opts for the exclusive inclusion in the settlement package through the state insurance houses, the costs must be limited to the respective financing, and the search for competitive advantages is focused on the other components of the marketing mix. If, on the other hand, the exit from the state settlement envelope of medical services is projected, based on the market analysis, some possibilities for other sources of financing are opened, with the possibility of satisfying the demand in higher conditions, by accessing additional packages. of optional private insurance, through direct payments, through partnerships with credit institutions, etc.

Given that the national insurance system is based as a source of rights on the obligation of fiscal contribution and not on the status of residence associated with territoriality, the distribution is no longer necessary to be insured at $100 \%$, although from a social point of view it remains a rule assumed. Practically, the economically developed areas, with populations that register higher incomes and implicitly provide higher taxes and duties, are mainly targeted for more developed medical services. For marketing reasons, it can be relied upon to encourage the territorial mobility of beneficiaries to benefit from services, to the detriment of a very extensive network of own units for which there may be a risk of lack of financial sustainability. For example, in disadvantaged areas, even with a significant population, but without taxpayers, the settlement ceilings of state insurance companies will be reached prematurely and the provision of services will be implicitly limited, which puts pressure on the distribution policy in the sense of limiting the possibilities of placing units that require large capital flows to provide developed services.

The promotion policy can be diversified, due to the fact that the national insurance system tends to cover the vast majority of categories of diseases. Therefore, the target groups of beneficiaries are multiple and diverse, meaning that the communication mix can vary substantially. Based on rigorous consumer research, communication strategies with a high degree of adaptation can be developed [13], which capitalize on their potential for attention across the spectrum of daily activities.

\section{Delivering Value in the Framework of the Private Insurance System}

In a system dominated by private health insurance, the majority takeover of health services by private insurance companies usually boosts the development of the medical field and increases the performance of services provided, but also induces a relatively high degree of social inequity, given the quintessential orientation towards profitability. Basically, a multitude of insurance policies can be developed in this dominant framework, the degree of personalization of the offer is high, the adaptation to specific needs and concrete possibilities of support being illustrated by the options for very varied clauses that can be attached to the policies. meets the needs of patients. 


\section{DOI: $10.17148 / / A R J S E T .2021 .8215$}

P R O D U C T
High flexibility
Stimulating the growth and innovation
Various possibilities to adapt and extend the offer
P R I C E
P L A C E
P R O MO T I O N
According to local needs and specifics
Multiple opportunities, both "pushing" and "puling"
Communication can target very specific groups
All involved organizations are interested in participating

Fig. 4 Marketing decisions under the private insurance system (Source: author drawing)

This system of organization has shown a good synergy with the engines of the market economy and, to some extent, with social responsibility, in the sense that the flexibility of the medical and health insurance offer. it could cover both direct financial and non-financial benefits [14]. The optional nature of these insurances can be both a support for the capitalist spirit of development, as well as an inherent risk factor for the well-being of individuals in the event of a sudden reduction in working capacity or the emergence of financial shortcomings. Based on these considerations, the operation within a reasonable safety margin can be ensured mainly in the conditions of a strong economy, but also of a compatible culture.

The product policy is in this case very diversified, with multiple possibilities to adapt to the area, structure and capacity of the market. This aspect, combined with the existence of free competition and the interest of capital providers for health investments, makes the innovation continuous, with a high speed of development of procedures and technologies [15].

Strategic marketing options regarding the price of services are predominantly based on cost-benefit analyses, taking into account the probabilistic impact of the risks of incidence, creditworthiness, the need to amortize investments, the costs of research and innovation, etc. The efforts of medical units to adapt to the needs of the market in profitable conditions are supported at the governmental level, usually through investments in large infrastructure and basic research, as well as by taking over to some extent the role of social protection for disadvantaged groups. whose care the state provides funding to health care providers. Basically, medical units can opt for a multitude of pricing strategies, for the design of which numerous convergent funding sources can be considered simultaneously.

Adapting the distribution to the needs of the demand carriers can be done without restrictions related to residence or tax contribution, but must be rigorously agreed with the specifics of the market. Integrating services so that locations are in synergy is extremely important to meet demand in profitable conditions, so that beneficiaries are as easily accessible as possible and medical units are provided with an optimal flow of activity in relation to the allocated resources [16]. At the same time, although the trend towards maximum efficiency may be strategically attractive, we must not lose sight of the fact that marketing requires first and foremost permanent adaptation to meet demand, and ensuring a high level of satisfaction ensures long-term benefits, especially in a market. highly competitive.

The options defined in terms of promotion policy are based on valuable information gathered through market research and can be adapted for both mass and focused messages, including direct marketing. It is relevant that the current technological evolution offers the possibility to capitalize on large volumes of data, with beneficial effects on the possibilities of adapting communication strategies, both on the sales promotion component and on the consumer attraction component, but at the same time the colossal importance of the protection of personal data in the medical field is taken into account.

\section{Delivering Value in the Framework of the Direct Interaction System}

Without completely replacing the existence of organized health care systems than in less fortunate cases, encountered in some states with volatile social, political and economic situations, the provision of medical services based on direct interactions usually has the role of meeting the needs of segments of patients to benefit from medical services in terms of their possibility and availability to pay directly and in full the equivalent value. The purposes are varied, for example aiming at the urgent need or, as the case may be, the personal desire to obtain certain types of services in very fast, nonbureaucratic conditions, the option for certain branches of medicine that have either not been included in a package 


\section{DOI: $10.17148 /$ IARJSET.2021.8215}

covered by public services. or by insurers, some premium medical services, the option for treatments that are legal in certain states, but in the one of residence are unconventional or are prohibited in practice and so on.

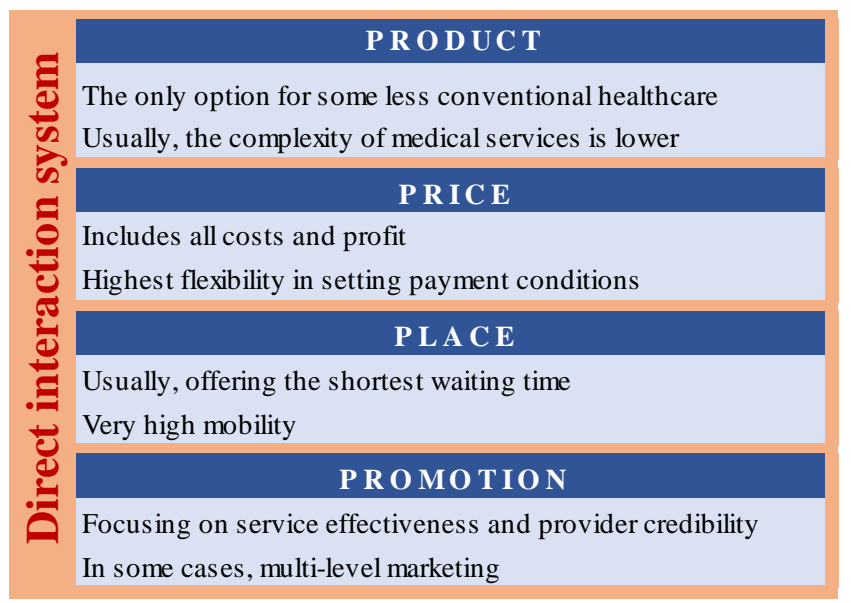

Fig. 5 Marketing decisions under the direct interaction system (Source: author drawing)

Even if capital flows are the fastest in these situations, the lack of a macro-organized system reduces the attractiveness of investments to develop long-term services. This, coupled with a mixture of more or less rigorous approaches to service delivery to meet demand, can cause problems for both beneficiaries and medical units, which face more than in previous systems the risk of major revenue blockages due to changes in demand, competition, own resources, etc. [17]. Practically, this system can punctually replace any of the elements that are part of other health systems, but is not able to completely replace any of these systems, given that it is inevitably lacking in long-term predictability. and inherently focuses on capitalizing on specific needs.

The product policy can be characterized by the desire to simplify as much as possible and to adapt to the level of even personalized services. The increasing complexity of the services offered in direct interaction can generate risks in terms of absorption capacity among potential beneficiaries, given that the architecture of these services addresses to a very small extent the general public, the emphasis being par excellence on patients who have individual ability to benefit from these services.

Regarding the price, it is formed on purely capitalist criteria, with minimal influences from some elements related to social protection, the improvement of health in the whole population and so on. The price must in this case directly include direct costs, indirect costs and profit. In extreme cases, it is possible that the entire framework for the provision of medical services in an area or field is in the grey area of the economy, on the periphery of taxable flows, for example in the case of payment of the doctor by the patient with agricultural products in poor rural areas.

The possibilities for adapting the distribution are relatively good, given that the system of direct interactions is based on the existence of a definite demand, which can be met directly. The opening of work points and the provision of medical services can be relatively easily adapted to places with the best represented and solvent segments of consumers. Similarly, if the beneficiaries are able to bear the costs, the providers can travel to the place of the request, the decision being based on purely economic reasoning. Distribution schemes for services based on multilevel marketing can also be implemented, focusing on the provision of coagulated groups of beneficiaries in certain areas, while expanding the network in terms of appropriate training by recording a relatively secure and involved demand.

Compared to the marketing mixes of the other systems, in this case the promotion is mainly focused on the effectiveness of medical services and the competence of providers. At the same time, given the minimum degree of structuring as a whole compared to previous systems, communication approaches are also less restricted, at least in terms of the elements addressed. Thus, although a consumer reaction based on the central processing of the transmitted information is usually desired, given the possibility of substantial competition on communication channels, as well as a possible limited interest, it may be possible to stimulate peripheral information processing by consumers, meaning that emotional activities can contribute substantially to the effectiveness of communication [18]. These aspects are all the more pronounced, as, as a rule, the demand for medical services is less crystallized due to the absence of an organized health system, with tradition. 


\section{CONCLUSION}

The study discussed some of the most appropriated marketing strategies for providing value for the patients by taking into account the specifics of four healthcare system cases. The modern economic reality, especially under effects of the globalization, shows that medical systems are not mutually-exclusive, but co-existent under different proportions, thus the need for an integrating approach being very actual. Each of these healthcare setups provides individual opportunities that business managers must capitalize on by directing the organizational resources strategically in order to satisfy patients and achieve financial success. Both theory and business experience show that no single strategy could be universally utilised in every region or period of time and that continuous research about the market environment is needed in order to dynamically and pro-actively adapt the healthcare services managers to the necessity of providing real value to the patients.

\section{REFERENCES}

[1]. World Health Organization, "Monitoring the building blocks of health systems: a handbook of indicators and their measurement strategies". Geneva, Switzerland: WHO Document Production Services, 2010.

[2]. T. Tulchinsky and E. Varavikova, “The New Public Health”, 3rd ed. San Diego, United States: Elsevier - Academic Press, 2014.

[3]. J. Kutzin, "Bismarck vs. Beveridge: is there increasing convergence between health financing systems?", in OECD Paris: First annual meeting of SBO network on health expenditure, 21-22 November 2011.

[4]. I. Papanicolas and P. Smith, "Conclusions", in Health System Performance Comparison, I. Papanicolas and P. Smith (Eds.). Berkshire, United Kingdom: Open University Press, pp. 335-371, 2013.

[5]. A. Thoeni, G. Marshall and S. Campbell, “A resource - advantage theory typology of strategic segmentation”, European Journal of Marketing, vol. 50(12), pp. 2192-2215, 2016.

[6]. P. Kotler, G. Armstrong, L.C. Harris and H. He, "Principles of Marketing", 8th European Ed. Harlow, United Kingdom: Pearson, 2020.

[7]. W. Beveridge, "Social Insurance and Allied Services". London, United Kingdom: Her Majesty's Stationery Office, 1942.

[8]. D. Mincă, "Public Health and Sanitary Management - Public Health”. Bucharest, Romania: University Publishing C. Davila, 2005.

[9]. A. Gheorghe, "Public hospitals reform - findings from the European space". Bucharest, Romania: Romanian Health Observatory, 2 , 2012.

[10]. G. Carrin, C. James and D. Evans, "Achieving universal health coverage: developing the health financing system", Geneva, Switzerland: World Health Organization, 2005.

[11]. N. Lameire, P. Joffe and M. Wiedemann, „Healthcare systems - an international review: an overview”, Nephrology Dialysis Transplantation, vol. 14(6), pp. 3-9, 1999.

[12]. R. Kulesher and E. Forrestal, "International models of health systems financing", Journal of Hospital Administration, Vol. 3(4), pp. 127-139, 2014.

[13]. P. Underhill, "Why We Buy, The Science of Shopping”. New York, United States: Simon \& Schuster Paperbacks, 2009.

[14]. G. Ridic, S. Gleason and O. Ridic, "Comparisons of Health Care Systems in the United States, Germany and Canada", Materia Socio Medica, vol. 24(2), pp. 112-120, 2012.

[15]. M. Morrisey, "Health Insurance", 2nd Ed. Chicago, United States: Health Administration Press, 2008.

[16]. F. White, „Primary Health Care and Public Health: Foundations of Universal Health Systems”, Medical Principles and Practice, vol. 24(2), pp. 103-116, 2015

[17]. J. Fincham, "Health Policy and Ethics". London, United Kingdom: Pharmaceutical Press, 2011.

[18]. F. Hansen, "Distinguishing between feelings and emotions in understanding communication effects", Journal of Business Research, vol. 58, pp. 1426-1436, 2005. 